\title{
Methane Activation by Group IVB Imido Complexes
}

\author{
Thomas R. Cundari ${ }^{1}$ \\ Contribution from the Department of Chemistry, Memphis State University, \\ Memphis, Tennessee 38152. Received May 21, 1992
}

\begin{abstract}
An ab initio study of methane activation by group IVB imido complexes, when coupled with available experimental data, reveals an interesting picture of this important reaction. Initial interaction of methane and $(\mathrm{H})_{2} \mathrm{M}=\mathrm{NH}$ leads to the formation of alkane complexes bound by $\approx 9 \mathrm{kcal} \mathrm{mol}^{-1}$. Experiment indicates that the polarity of the metal-ligand bond upon which the $\mathrm{C}-\mathrm{H}$ is activated plays an important role in facilitating subsequent scission. Calculations support this hypothesis and suggest that formation of the alkane complex acts to increase $\mathrm{C}^{\delta-} \mathrm{H}^{\delta+}$ polarization, setting the stage for $\mathrm{C}-\mathrm{H}$ cleavage. Calculated methane elimination barriers for $(\mathrm{H})_{2} \mathrm{M}\left(\mathrm{CH}_{3}\right)\left(\mathrm{NH}_{2}\right)(\mathrm{M}=\mathrm{Ti}, \mathrm{Zr}, \mathrm{Hf})$ are in good agreement with experimental models in terms of absolute numbers and trends as a function of metal. Calculated methane activation barriers follow the order $\mathrm{Ti}>\mathrm{Zr}>\mathrm{Hf}$, in line with calculated exothermicities. Calculated geometries indicate a late transition state for methane elimination, in agreement with experimentally determined activation parameters. The TSs have a kite-shaped geometry with an obtuse angle about the $\mathrm{H}$ of the $\mathrm{C}-\mathrm{H}$ bond being activated $\left(\mathrm{H}_{t}\right)$ and a short $\mathrm{MH}_{\mathrm{t}}$ distance, 1-2\% greater than normal. The short $\mathrm{MH}_{\mathrm{t}}$ distance suggests a stabilizing interaction, supported by a positive bond overlap population. Calculation of the intrinsic reaction coordinate demonstrates the importance of agostic interactions between $\mathrm{N}-\mathrm{H}$ and $\mathrm{M}$ along the reaction coordinate.
\end{abstract}

\begin{abstract}
Introduction
The functionalization of alkanes by discrete, well-characterized organometallic complexes has attracted the attention of numerous chemists. $^{2}$ Much of the impetus for this work has been provided by the search for selective organic synthetic reagents and the ability to convert petrochemical feedstocks into more valuable commodity chemicals. ${ }^{2}$ Methane, the least reactive and most plentiful of the alkanes, has been described as the "Holy Grail" of C-H activation. ${ }^{3}$ Transition-metal complexes used to effect concerted $\mathrm{C}-\mathrm{H}$ activation are of two main classes. The first group consists of low-valent late transition-metal complexes, and the activation mechanism involves oxidative addition. A large body of experimental and theoretical work has focused on these systems and oxidative addition. ${ }^{4} \mathrm{C}-\mathrm{H}$ activation is also effected by high-valent $\left(d^{0}\right.$ and $d^{0} f^{n}$ ) metals, predominantly of the early $d$ or $f$ block. ${ }^{5}$ Representative examples of high-valent methane activators include the lanthanide and group IIIB metallocenes, ${ }^{6}$ organoactinides, and group IVB imido complexes. ${ }^{8,9}$ Their high reactivity hinders direct experimental probing of the potential energy surface for methane activation. Thus, computation can play an important role in "isolating" important species, submitting them to study, and understanding the interactions which give rise to an effective methane activation system. To this end we have initiated studies
\end{abstract}

(1) E-mail: cundarit@memstvxl.memst.edu.

(2) Activation and Functionalization of Alkanes; Hill, C. L., Ed,; Wiley: New York, 1989.

(3) Rothwell, I. P., in ref $2, \mathrm{p} 151$.

(4) Numerous references to the original literature, experimental and computational, for the activation of $\mathrm{C}-\mathrm{H}$ bonds by low-valent transition-metal complexes can be found in Saillard, I.-Y.; Hoffmann, R. J. Am. Chem. Soc $1984,106,2006$.

(5) Nonconcerted (heterolytic ${ }^{5 a}$ and homolytic $\left.{ }^{5 b, c}\right) \mathrm{C}-\mathrm{H}$ activation pathways are also well known, as is methane activation by gas-phase metal ions. ${ }^{5 d, e}$ (a) Olah, G. A. Acc. Chem. Res. 1987, 20, 422. (b) Wayland, B. B.; Ba, S. Sherry, A. E. J. Am. Chem. Soc. 1991, 113, 5305. (c) Liu, H.; Liu, R. S.; Liew, K. W.; Johnson, R. E.; Lunsford, J. H. J. Am. Chem. Soc. 1984, 106, 4117. (d) Armentrout, P. B.; Beauchamp, J. L. Acc. Chem. Res. 1989, 22 315. (e) Simões, J. A. M.; Beauchamp, J. L. Chem. Rev. 1990, 90, 629

(6) (a) Thompson, M. E.; Bercaw, J. E. Pure Appl. Chem. 1984, 56, 1. (b) Thompson, M. E.; Baxter, S. M.; Bulls, A. R.; Burger, B. J.; Nolan, M. C.; Santarsiero, B. D.; Schaefer, W. P.; Bercaw, J. E. J. Am. Chem. Soc. 1987, 109, 203. (c) Watson, P. L.; Parshall, G. W. Acc. Chem. Res. 1985, 18, 51 and references therein. (d) Watson, P. L. In Selective Hydrocarbon Activation; Davies, J. A., Ed; VCH: New York, 1990; p 80

(7) (a) Fendrick, C. M.; Marks, T. J. J. Am. Chem. Soc. 1986, 106, 2214 (b) Fendrick, C. M.; Marks, T. J. J. Am. Chem. Soc. 1986, 108, 425.

(8) (a) Cummins, C. C.; Baxter, S. M.; Wolczanski, P. T. J. Am. Chem. Soc. 1988, 110,8731 . (b) Cummins, C. C. Schaller, C. P.; Van Duyne, G D.; Wolczanski, P. T.; Chan, A. W. E.; Hoffmann, R. J. Am. Chem. Soc. 1991, 113, 2985. (c) Walsh, P. J.; Hollander, F. J.; Bergman, R. G. J. Am. Chem. Soc. 1988, 110, 8729 .

(9) The most researched family of high-valent, multiply bonded complexes which effect $\mathrm{C}-\mathrm{H}$ activation are the biochemically important metal-oxo $\left(\mathrm{L}_{n} \mathrm{M}=\mathrm{O}\right)$ complexes. Holm, R. H. Chem. Rev. 1987, 87, 1401 . of high-valent methane activation systems to complement their more well-studied counterparts ${ }^{4,5}$ and the growing body of experimental data. ${ }^{6-9}$

Rothwell has reviewed the literature of high-valent $\mathrm{C}-\mathrm{H}$ activation complexes up to $1987 .{ }^{3}$ The high-valent, often $\mathrm{d}^{0}$, nature of the metal precludes oxidative addition. Proposed mechanisms, therefore, involve four-center $([2+2])$ transition states (TSs) in which the formal oxidation state of the metal does not change. ${ }^{3}$ The activation of $\mathrm{X}-\mathrm{H}$ bonds by early, high-valent complexes has been studied computationally, although to a lesser extent than low-valent systems. Goddard and Steigerwald have looked at the reactions of $\mathrm{H}_{2}$ with the model complexes $\mathrm{Cl}_{2} \mathrm{MH}(\mathrm{M}=\mathrm{Sc}, \mathrm{Ti})$ and $\left[\mathrm{Cl}_{2} \mathrm{TiH}\right]^{+} .10$ Rappe has extensively researched the reactivity of $\mathrm{Ti}$ and Sc complexes. ${ }^{11}$ Hoffmann et al. have performed an extended Huckel analysis of the $\mathrm{Cp}_{2} \mathrm{LuR}(\mathrm{R}=\mathrm{H}, \mathrm{Me})$ system..$^{12}$ Cundari has reported an ab initio study of the reaction (N$\left.\mathrm{H}_{2}\right)_{2} \mathrm{Z}=\mathrm{NH}+\mathrm{H}_{2} \rightarrow\left(\mathrm{NH}_{2}\right)_{3} \mathrm{ZrH}$ and its microscopic reverse. ${ }^{13}$ These computational studies, at different levels of theory, all point to four-center transition states for $\mathrm{H}-\mathrm{X}$ bond activation. The geometries of the four-center TSs are also similar, with an obtuse angle about $H_{t}(1)$ and the three remaining angles all acute. In

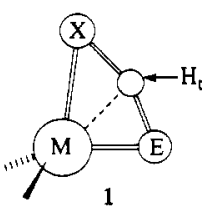

each case a relatively short metal (M)-transannular hydrogen $\left(\mathrm{H}_{t}\right)$ distance is found, suggestive of a bonding interaction. Goddard and Steigerwald ${ }^{10}$ conclude that no formal bond exists between the metal and $\mathrm{H}_{t}$ in the TS for $\mathrm{Cl}_{2} \mathrm{ScH}+\mathrm{H}_{2}$. A stabilizing interaction, albeit smaller than a normal metal-terminal hydride bond, was indicated in the works of Hoffmann et al. ${ }^{12}$ (the $\mathrm{LuH}_{\mathrm{t}}$ overlap population is calculated to be $0.06^{14}$ ) and Cundari..$^{13}$

Wolczanski et al ${ }^{8 \mathrm{a}}$ have reported that tris(amido)alkylzirconium complexes $\left(\mathrm{NHSi}^{\prime}\right)_{3} \mathrm{ZrR}\left(\mathrm{Si}^{\prime}=(t-\mathrm{Bu})_{3} \mathrm{Si} ; \mathrm{R}=\mathrm{CD}_{3}\right.$, cyclo- $\left.\mathrm{C}_{6} \mathrm{H}_{11}\right)$,

(10) Goddard, W. A.; Steigerwald, M. L. J. Am. Chem. Soc. 1984, 106, 308 and references therein.

(11) (a) Rappé, A. K. Organometallics 1990, 9, 466. (b) Rappé. A. K. J. Am. Chem. Soc. 1987, 109, 5605. (c) Rappé, A. K.; Upton, T. H. J. Am. Chem. Soc. 1985, 107, 1206. (d) Rappé, A. K. Organometallics 1987, 6, 354.

(12) Hoffmann, R.; Saillard, J.-Y.; Rabaâ, H. J. Am. Chem. Soc. 1986, $108,4327$.

(13) Cundari, T. R. Int. J. Quantum Chem., Proc. Sanibel Symp. 1992, 26,793 .

(14) Preliminary results from our laboratories on the $\mathrm{Cl}_{2} \mathrm{MCH}_{3}+\mathrm{CH}_{4}$ reaction, models of the metallocene systems, ${ }^{6}$ show substantial stabilizing $\mathbf{M H}$ interaction in the TS for methane activation $(\mathrm{M}=\mathrm{Sc}, \mathrm{Y}, \mathrm{Lu})$, as indicated by positive Mulliken bond overlap populations $(\approx 0.2)$. 
when heated in the presence of methane ( $3 \mathrm{~atm}$ ), yield the corresponding methyl complex ( $\left.\mathrm{NHSi}^{\prime}\right)_{3} \mathrm{ZrMe}$ plus an equivalent of alkane. Reaction of the tris(amido)methyl complex with $\mathrm{D}_{2}$ gives $\left(\mathrm{NHSi}^{\prime}\right)_{2}\left(\mathrm{NDSi}^{\prime}\right) \mathrm{ZrD}$ and methane. The data support a bis(amido)imido intermediate $\left(\left(\mathrm{NHSi}^{\prime}\right)_{2} \mathrm{Zr}=\mathrm{NSi}^{\prime}\right)$ capable of activating $\mathrm{H}_{2}$ (or $\mathrm{RH}$ ). Two pathways can be envisioned for the conversion of the bis(amido)imido to the tris(amido)alkyl. The first route is the 1,2-addition of $\mathrm{C}-\mathrm{H}$ across the $\mathrm{Zr}=\mathrm{N}$ bond of the bis(amido)imido to form tris(amido)alkyl directly. Addition of $\mathrm{C}-\mathrm{H}$ across a $\mathrm{Zr}$-amido bond followed by rapid $\mathrm{H}$ transfer is another possibility. ${ }^{8}$ The calculated barrier for $\mathrm{H}_{2}$ addition across $\mathrm{Zr}=\mathrm{N}$ is half that for addition across $\mathrm{Zr}-\mathrm{N}$ in $\left(\mathrm{NH}_{2}\right)_{2} \mathrm{Zr}=\mathrm{NH} .^{13}$ The direct pathway is also supported by the reactivity of related $\mathrm{Cp}_{2} \mathrm{Zr}=\mathrm{NR}$ complexes. ${ }^{8 \mathrm{c}}$ Walsh et al. ${ }^{8 \mathrm{c}}$ have demonstrated that zirconocene-imido complexes $\mathrm{Cp}_{2} \mathrm{Zr}=\mathrm{NR}$ are capable of activating the $\mathrm{C}-\mathrm{H}$ bond of benzene. In the zirconocene case, the presence of the imido intermediate was confirmed by $\mathrm{X}$-ray crystallography.

Reported Ti-imido complexes display reactivity somewhat different from that of their $\mathrm{Zr}$ counterparts. ${ }^{8 \mathrm{~b}, 15}$ When $\left(\mathrm{Ar}^{\prime \prime} \mathrm{O}\right)_{2}\left(\mathrm{py}^{\prime}\right)_{2} \mathrm{Ti}=\mathrm{NPh}\left(\mathrm{Ar}^{\prime \prime}=2,6\right.$-diisopropylphenyl; $\mathrm{py}^{\prime}=$ 4-pyrrolidinopyridine) is refluxed in benzene for several hours, no $\mathrm{C}-\mathrm{H}$ activation products are observed. Wolczanski et al. ${ }^{8 \mathrm{~b}}$ have studied the reactivity of $\mathrm{Ti}$-imido complexes; activation of benzene was effected by these complexes, but not methane. However, a related $\mathrm{Ti}$-imido complex $\left(\left(\mathrm{Si}^{\prime} \mathrm{O}\right)_{2} \mathrm{Ti}=\mathrm{NSi}{ }^{\prime}\right)$ with different ancillary ligands has recently been shown to activate methane. ${ }^{16}$ Increased steric congestion in five-coordinate ${ }^{15}$ versus three-coordinate $^{8 \mathrm{~b} .16} \mathrm{Ti}$ complexes cannot be ruled out as a factor in the observed reactivity differences.

For the present work, the transition metals of interest are from group IVB, with model complexes of the from $(X)_{2} \mathrm{M}=\mathrm{NH},(\mathrm{M}$ $=\mathrm{Ti}, \mathrm{Hf}, \mathrm{X}=\mathrm{H}$; and $\mathrm{M}=\mathrm{Zr}, \mathrm{X}=\mathrm{H}, \mathrm{NH}_{2}, \mathrm{Cl}$ ). As part of a continuing focus on the electronic structure and reactivity of multiply bonded transition-metal complexes, ${ }^{17}$ a computational study of the activation of methane by group IVB imido complexes was initiated. The results for the activation of methane (and the reverse reaction, methane extrusion) by group IVB imido complexes are reported here. Group IVB imido complexes were chosen because previous work ${ }^{13,17}$ has shown that the chemistry of these systems can be accurately described and remain computationally tractable.

\section{Computational Methods}

The calculations described herein employ the $a b$ initio quantum chemistry program GAMESS. ${ }^{18}$ Effective core potentials (ECPs) replace the chemically less important core electrons and thus make calculations feasible for all rows of the transition series. The ECPs and valence basis sets of Stevens, Basch, Krauss, and Jasien (SBKJ) ${ }^{19}$ are used for heavy atoms, while Hs are described with the $-31 G$ basis set. The ECP replaces the innermost core orbitals for the metals and all core orbitals for the main-group elements. Thus, the $n s, n \mathrm{p}, n \mathrm{~d},(n+1) \mathrm{s}$, and $(n+1) \mathrm{p}$ are treated explicitly for the $\mathrm{d}$ block; for the main-groups elements, $n$ s and $n \mathrm{p}$ are treated explicitly. For the transition metals, the SBKJ valence basis sets are quadruple- and triple- $\zeta$ for the $s, p$, and $d$ shells, respectively; main-group elements have a double- $\zeta$ valence basis. The transition-metal potentials are generated from all-electron Dirac-Fock

(15) Hill, J. E.; Profilet, R. D.; Fanwick, P. E.; Rothwell, I. P. Angew Chem., Int. Ed. Engl. 1990, 29,664.

(16) Wolczanski, P. T., Dept. of Chemistry, Cornell University, personal communication.

(17) (a) Cundari, T. R, J, Am. Chem. Soc. 1992, 114, 7879. (b) Cundari T. R. Gordon M. S. J Am. Chem. Soc 1991, 113,5231. (c) Cundari, T. R.; Gordon, M. S. Organometallics 1992, 11, 55. (d) Cundari, T. R.; Gordon, M. S. J. Am. Chem. Soc. 1992, 114,539 . (e) Cundari, T. R.; Gordon, M S. J. Phys. Chem. 1992, 96, 631. (f) Cundari, T. R.; Gordon, M. S. Organometallics $1992,11,3122$.

(18) GAMESS (General Atomic and Molecular Electronic Structure System): Schmidt, M. W.; Baldridge, K. K.; Boatz, J. A.; Jensen, J. H.; Koseki, S.; Gordon, M. S.; Nguyen, K. A.; Windus, T. L.; Elbert, S. T. QCPE Bull. 1990, 10, 52 .

(19) Krauss, M.; Stevens, W. J.; Basch, H.; Jasien, P. G. Can. J. Chem 1992, 70,612. calculations and thus include Darwin and mass velocity relativistic corrections, while spin-orbital coupling is averaged out in potential generation as described in the original paper. ${ }^{19}$ Basis sets for heavy main-group elements are augmented with a d polarization function. ${ }^{20}$ Geometry optimizations employ the method of Baker ${ }^{21}$ and, unless stated otherwise, are done at the restricted HartreeFock (RHF) level for closed-shell singlets. The present combination of ECPs, basis sets, and level of theory has been thoroughly validated for a large number of transition-metal complexes, particularly with respect to geometric prediction. ${ }^{13,17}$ Bond lengths and bond angles involving transition metals are typically predicted within $1-3 \%$ of experimental models. Further comparisons between theory and experiment are presented below, with more extensive results elsewhere. ${ }^{13,17}$ Frequencies are calculated at stationary points to identify them as minimia (zero imaginary frequencies) or transition states (one imaginary frequency). Plotting the imaginary frequency and perturbing the geometry along this mode (in the forward or reverse direction), followed by reoptimization, is used to assess which transition state (TS) connects which minima. In some cases, the intrinsic reaction coordinate (IRC) ${ }^{22}$ is followed from the TS toward reactants and products. Intrinsic stretching frequencies are calculated using the method of Boatz and Gordon. ${ }^{23}$

Previous work has clearly demonstrated that $\mathrm{d}^{0}$ transition-metal complexes like those studied here are well described at the single determinant level; thus, geometric parameters are accurately predicted since a flexible basis set is used. ${ }^{13,17}$ Calculated energetics will usually be poor if electron correlation is ignored. For species described well at the single determinant level, the correlation contribution can be treated as a perturbation to the HF energy. For this reason, the correlation energy is calculated using second-order Møller-Plesset (MP2) theory. ${ }^{20}$ Core electrons are not included in the MP2 active space. All quoted energies are determined at the MP2 level using the RHF geometries with zero-point energy (ZPE) correction included.

A series of test calculations were carried out on the TS for $(\mathrm{H})_{2} \mathrm{Zr}=\mathrm{NH}+\mathrm{CH}_{4} \rightarrow(\mathrm{H})_{2} \mathrm{Zr}\left(\mathrm{CH}_{3}\right)\left(\mathrm{NH}_{2}\right)$ to assess the importance of correlation for the prediction of TS geometry. $\mathrm{MCSCF}^{24}$ and RHF transition states are very similar. The bonds which break and form in the TS differ by an average of only 0.03 $\AA$, while exocyclic bonds change even less. The coefficient of the Hartree-Fock $\left(C_{\mathrm{HF}}\right)$ configuration at the MCSCF-optimized TS is $\approx 92 \%$. As a comparison, the TS for an organic analogue (the addition of an $\mathrm{N}-\mathrm{H}$ bond of ammonia across the $\mathrm{C}=\mathrm{O}$ bond of formaldehyde, ${ }^{25}$ ) has $C_{\mathrm{HF}} \approx 93 \%$ at a comparable level of theory. Thus, the MCSCF results support the present approach, MP2 energies at RHF geometries, used with great success in studies of main-group reactivity. ${ }^{26,27}$

\section{Result and Discussion}

1. Reactants and Products. The geometry and electronic structure of transition-metal imido complexes, including the reactants in the present study, have been discussed elsewhere; ${ }^{13,17 a}$ only the highlights are sketched here. The geometry of methane is, of course, well known. As expected for early imido complexes,

(20) Pople, J. A.; Hehre, W. J.; Radom, L.; Schleyer, P. v. R.; Ab-Initio Molecular Orbital Theory; Wiley: New York, 1986.

(21) Baker, J. J. Comput. Chem. 1986, 7, 385.

(22) (a) Truhlar, D. G.; Steckler, R.; Gordon, M. S. Chem. Rev. 1987, 87, 217. (b) Truhlar, D. G.; Gordon, M. S. Science 1990, 249, 491

(23) Boatz, J. A.; Gordon, M. S. J. Phys. Chem. 1989, 93, 1819.

(24) (a) $\mathrm{MCSCF}=$ multiconfiguration self-consistent field. Ruedenberg, K.; Schmidt, M. W.; Dombek, M. M.; Elbert, S. T. Chem. Phys. 1982, 71 , $41,51,65$. (b) In the MCSCF optimization, eight electrons in eight MOs are correlated, the orbitals and electrons derived from the metal-imido $\sigma$ and $\pi$ bonds, $\sigma_{\mathrm{CH}}$, plus their antibonding counterparts.

(25) Jensen, J. H.; Baldridge, K. K.; Gordon, M. S. J. Phys. Chem. 1992, 96,8340 .

(26) Gordon, M. S.; Francisco, J.; Schlegel, H. B. Adv. Silicon Chem. In press.

(27) (a) A similar approach (RHF wavefunctions for the evaluation of stationary points, followed by the calculation of energetics at correlated levels) has been successfully employed by $\mathrm{Rappe}^{1 / \mathrm{a}, b}$ in his studies of $\mathrm{Cl}_{2} \mathrm{ScH}$ reactivity (using generalized valence bond theory) and Koga and Morokuma $2 \%$ for the $\mathrm{RhCl}\left(\mathrm{PH}_{3}\right)_{2}+\mathrm{CH}_{4}$ reaction (using MP2). (b) Koga, N.; Morokuma, K. J. Phys. Chem. 1990, 94, 5454 . 

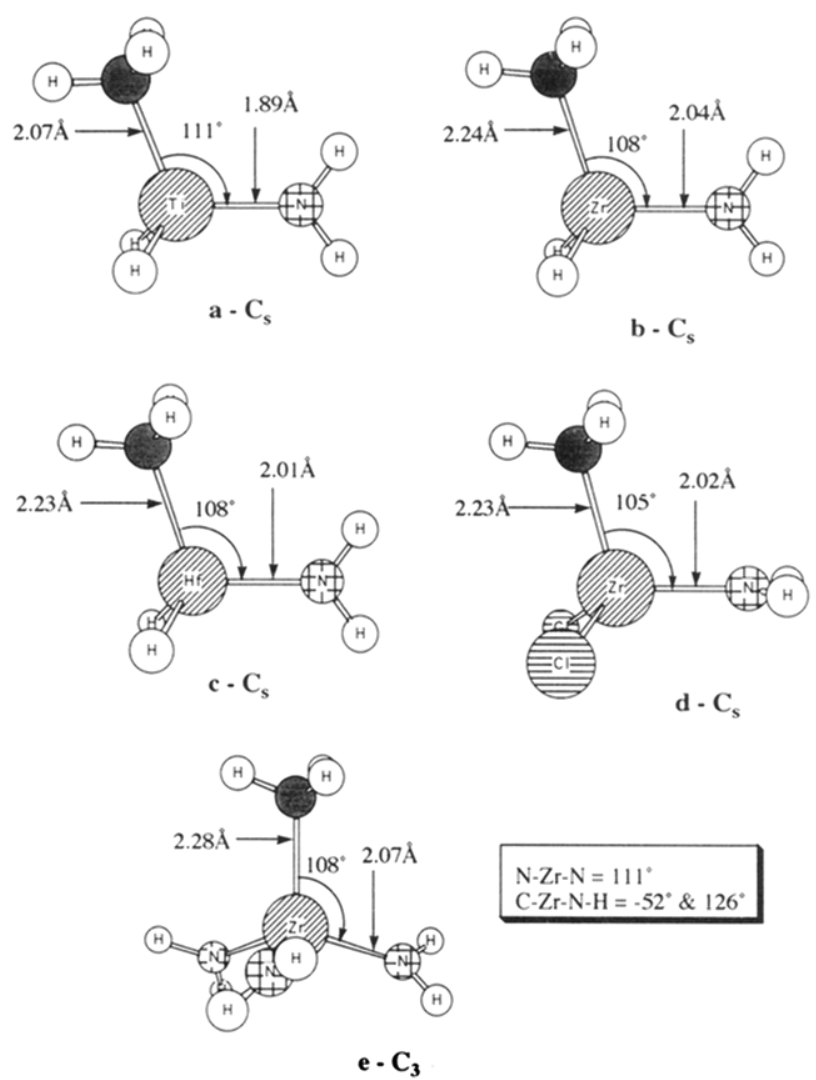

$$
\mathbf{e} \cdot \mathbf{C}_{\mathbf{3}}
$$

Figure 1. Geometries of the methyl(amido) products were calculated as described in the text. Other geometric parameters are similar to values reported elsewhere. ${ }^{17}$

the imido (NH) ligand is coordinated in a linear fashion. ${ }^{28}$ Metal-imido bond lengths are $1.65(\mathrm{Ti}), 1.80(\mathrm{Zr})$, and $1.79 \AA$ $(\mathrm{Hf})$ for the parent complexes $(\mathrm{H})_{2} \mathrm{M}=\mathrm{NH}$. Calculated $\mathrm{Zr}$-imido bond lengths in the dichloroimido and bis(amido)imido are 1.79 and $1.83 \AA$, respectively. Note the lengthening of the $\mathrm{Zr}$-imido bond upon replacement of hydrido with amido ligands. ${ }^{29}$ Metal-ligand and $\mathrm{N}-\mathrm{H}$ bond lengths and bond angles are typical. ${ }^{17}$ The Ti-imido and $\mathrm{Zr}$-dichloroimido minima are $C_{2 v}$ (i.e., trigonal planar about the metal), while $(\mathrm{H})_{2} \mathrm{M}=\mathrm{NH}(\mathrm{M}=\mathrm{Zr}, \mathrm{Hf})$ and $\left(\mathrm{NH}_{2}\right)_{2} \mathrm{Zr}=\mathrm{NH}$ possess slightly pyramidal $\left(C_{s}\right)$ geometries.

The calculated $\mathrm{Zr}=\mathrm{N}$ stretching frequency for $\left(\mathrm{NH}_{2}\right)_{2} \mathrm{Zr}=\mathrm{NH}$ is $955 \mathrm{~cm}^{-1}$; it is important to note that this is not an intrinsic stretching frequency and that other normal modes are mixed in. Vibrational frequencies calculated at the RHF level are usually scaled by 0.9 to account for electron correlation effects $\left(\nu_{\mathrm{Zr}=\mathrm{N}^{-}}\right.$ (scaled) $\left.=860 \mathrm{~cm}^{-1}\right) \cdot{ }^{30}$ An IR band at $865 \mathrm{~cm}^{-1}$ was assigned to the $\mathrm{Zr}=\mathrm{N}$ stretch of the THF adduct of $\left(\mathrm{NHSi}^{\prime}\right){ }_{2} \mathrm{Zr}=\mathrm{NSi}^{\prime}{ }^{29}$ The coordination of a Lewis base to the metal is another factor to be considered. The coordination of Lewis bases (e.g., $\mathrm{NH}_{3}$ and $\mathrm{H}_{2} \mathrm{O}$ ) to metal-imidos lowers the calculated metal-imido stretching frequency by only $10-20 \mathrm{~cm}^{-1}$ depending on the Lewis base and the metal. ${ }^{17 a}$ Thus, our calculated $\nu_{\mathrm{Z}=\mathrm{N}}$ is in agreement with the assignment of the IR band at $865 \mathrm{~cm}^{-1}$ to a $\mathrm{Zr}=\mathrm{N}$ stretch. ${ }^{8 \mathrm{a}}$

The products of methane activation are pseudotetrahedralmethyl(amido) complexes, Figure 1. While the dihydridoamido complexes prefer an eclipsed conformation of $\mathrm{NH}_{2}$ relative to the $\mathrm{M}-\mathrm{C}$ bond, $(\mathrm{Cl})_{2} \mathrm{Zr}\left(\mathrm{CH}_{3}\right)\left(\mathrm{NH}_{2}\right)$ is staggered and $\mathrm{Zr}\left(\mathrm{NH}_{2}\right)_{3}\left(\mathrm{CH}_{3}\right)$ is $C_{3}$, Figure 1. The various rotamers are within $1-2 \mathrm{kcal} \mathrm{mol}^{-1}$

(28) Nugent, W. A.; Mayer, J. M. Metal-Ligand Multiple Bonds; Wiley: New York, 1989.

(29) A preliminary X-ray structural analysis (Wolczanski, P. T., unpublished results $)$ of $\left(\mathrm{NHSi}^{\prime}\right)_{2}(\mathrm{THF}) \mathrm{Zr}\left(=\mathrm{NSi}^{\prime}\right)$ reveals a geometry unlike any other reported $\mathrm{Zr}$-imido complex, i.e., $\mathrm{Zr}=\mathrm{N}=1.97 \mathrm{~A}, \mathrm{Zr}=\mathrm{NSi}=157^{\circ}$. Further studies of this interesting complex will be forthcoming.

(30) Pople, J. A.; Schlegel, H. B.; Krishnan, R.; DeFrees, D. F.; Binkley, J. S.; Frisch, M. J.; Whiteside, R.; Hout, R. F.; Hehre, W. J. Int. J. Quantum Chem., Proc. Sanibel Symp. 1981, 15, 269.
Table I. Calculated Enthalpic Data ${ }^{a}$

\begin{tabular}{lcccc}
\hline imido reactants & $\Delta H^{*}$ act & $\Delta H^{*}$ elim & $\Delta H_{\text {rxn }}$ & $\Delta H_{\text {add }}$ \\
\hline$(\mathrm{H})_{2} \mathrm{Ti}=\mathrm{NH}$ & 14.5 & 23.4 & 8.9 & 8.9 \\
$(\mathrm{H})_{2} \mathrm{Zr}=\mathrm{NH}$ & 14.1 & 34.1 & 20.0 & 8.7 \\
$(\mathrm{H})_{2} \mathrm{Hr}=\mathrm{NH}$ & 7.3 & 38.0 & 30.7 & 9.3 \\
$\left(\mathrm{NH}_{2}\right){ }_{2} \mathrm{Zr}=\mathrm{NH}$ & 12.0 & 33.4 & 21.4 & $\mathrm{nc}^{b}$ \\
$(\mathrm{Cl})_{2} \mathrm{Zr}=\mathrm{NH}$ & 12.9 & 34.9 & 22.0 & $\mathrm{nc}^{b}$ \\
\hline
\end{tabular}

${ }^{a}$ Calculated enthalpic data $\left(\mathrm{kcal} \mathrm{mol}^{-1}\right)$ for $(\mathrm{X})_{2} \mathrm{M}=\mathrm{NH}+\mathrm{CH}_{4} \rightarrow$ $(\mathrm{X})_{2} \mathrm{M}\left(\mathrm{CH}_{3}\right)\left(\mathrm{NH}_{2}\right)$ using methods described in the text. $\Delta H^{*}$ act is the barrier for $\mathrm{C}-\mathrm{H}$ activation by imido reactant; $\Delta H^{*}$ elim is the barrier for the reverse reaction, i.e., methane elimination from methyl(amido)product; $\Delta H_{\mathrm{rxn}}$ is the reaction enthalpy; $\Delta H_{\mathrm{add}}$ is the energy of the CT complex 2 below separated products. All quantities are measured versus separated reactants. ${ }^{b} \mathrm{nc}=$ not calculated.

at the RHF level (with ZPE correction). The calculated metal-carbon distances are in good agreement with the mean bond distances in the homoleptic tetrabenzyl complexes: $\mathrm{TiC}=2.07$ $\AA(2.13(4) \AA$ exptl), $\mathrm{ZrC}=2.24 \AA$ (2.27 (1) $\AA$ exptl), $\mathrm{HfC}=$ $2.23 \AA(2.25(1) \AA$ exptl $){ }^{31 \mathrm{a}}$ Tetrakis $(N, N$-dimethylamido $)-\mathrm{Ti}$ and $-\mathrm{Zr}$ complexes have recently been characterized by electron diffraction techniques, yielding $\mathrm{Ti}-\mathrm{N}=1.917$ (3) $\AA$ and $\mathrm{Zr}-\mathrm{N}$ $=2.071(11) \AA .{ }^{316}$ The complex $\mathrm{Ti}\left(\mathrm{N}(\mathrm{Me}) \mathrm{Si}(\mathrm{Me}){ }_{2} \mathrm{Si}(\mathrm{Me})_{2} \mathrm{~N}\right.$ $(\mathrm{Me}))_{2}$ has Ti-amido bond lengths from 1.902 to $1.909 \AA$, ${ }^{31 \mathrm{c}}$ while $\mathrm{Cl}_{3} \mathrm{TiNEt}_{2}$ has $\mathrm{TiN}=1.852 \AA{ }^{31 \mathrm{c}}$ The calculated metal-amido bond lengths ( $\mathrm{TiN}=1.89 \AA ; \mathrm{ZrN}=2.04 \AA ; \mathrm{HfN}=2.01 \AA$ ) in the methyl(amido) complexes, Figure 1, are thus in good agreement with experiment.

The calculated exothermicity of the reaction $(\mathrm{H})_{2} \mathrm{M}=\mathrm{NH}+$ $\mathrm{CH}_{4} \rightarrow(\mathrm{H})_{2} \mathrm{M}\left(\mathrm{CH}_{3}\right)\left(\mathrm{NH}_{2}\right)$ increases as the metal becomes heavier: $\Delta H_{\mathrm{rxn}}\left(\mathrm{kcal} \mathrm{mol}^{-1}\right)=8.9(\mathrm{Ti}), 20.0(\mathrm{Zr})$, and $30.7(\mathrm{Hf})$, Table I. The replacement of the two hydrido ligands in the $\mathrm{Zr}$ complex with two chloro or amido ligands increases the exothermicity of the reaction slightly. The dichloroimido complex has $\Delta H_{\mathrm{rxn}}=21.4 \mathrm{kcal} \mathrm{mol}^{-1}$; the bis(amido)imido complex has $\Delta H_{\mathrm{rxn}}=22.0 \mathrm{kcal} \mathrm{mol}^{-1}$. Direct kinetic and thermodynamic information is limited for the addition of the methane $\mathrm{C}-\mathrm{H}$ bond across the metal-imido linkage, since this step is swift relative to the rate-determining elimination of alkane from the tris(amido)alkyl precursor ${ }^{8 a}$ Methane activation ostensibly entails the formation of a $\mathrm{M}-\mathrm{CH}_{3}$ bond at the expense of a $\mathrm{MN} \pi$-bond, with a constant main-group contribution (i.e., $\mathrm{BE}\left(\mathrm{H}_{3} \mathrm{CH}\right)-\mathrm{BE}(\mathrm{HNH})$ $\left.\approx 13 \mathrm{kcal} \mathrm{mol}^{-1}\right)$. We propose as one possible reason for the greater exothermicity the greater driving force of a strong $\mathrm{M}-\mathrm{CH}_{3}$ bond $\left(\mathrm{Hf}>\mathrm{Zr}>\mathrm{Ti}^{32 \mathrm{a}}\right.$ ) coupled with a nearly constant $\mathrm{MN}$ $\pi$-bond strength. ${ }^{32 b}$ Given the scarcity of data, experimental or computational, for high-valent systems, this conclusions is quite speculative and, perhaps more than anything, underscores the need for more research in this area.

2. Initial Interaction of Reactants and Products. Alkane complexes are thought to be important intermediates in $\mathrm{C}-\mathrm{H}$ activation by low-valent complexes. ${ }^{33}$ Burkey et al. ${ }^{34}$ have measured appreciable binding energies, $10-12 \mathrm{kcal} \mathrm{mol}^{-1}$, for the

(31) (a) The tetrabenzyl complexes of $\mathrm{Ti}, \mathrm{Zr}$, and $\mathrm{Hf}$ have distortions which are suggestive of interaction between the phenyl rings and the metal, hence the wide range of $\mathrm{M}-\mathrm{C}$ bond lengths, particularly for $\mathrm{Ti}(\mathrm{bz})_{4}$. Davies, G. R.; Jarvis, J. A. J.; Kilbourn, B. T. J. Chem. Soc. Chem. Commun. 1971, 1511. (b) Haaland, A.; Rypdal, K.; Volden, H. V.; Andersen, R. A. J. Chem. Soc., Dalton Trans. 1992, 891. Hagen, K.; Holwill, C. J.; Rice, D. A.; Runnacles, J. F. Inorg. Chem. 1988, 27, 2032. (c) Lappert, M. F.; Power, P. P.; Sangerand, A. R.; Srivasta, R. C. Metal and Metalloid Amides; Ellis Horwoood: Chichester, 1980, p 475.

(32) (a) This assumption is based on the order in mean bond dissocation energies for the homoleptic tetraneopentyl complexes of the group IVB metals. ${ }^{\mathrm{se}} D(\mathrm{Ti}-\mathrm{C})=198 \mathrm{~kJ} \mathrm{~mol}^{-1} ; D(\mathrm{Zr}-\mathrm{C})=249 \mathrm{~kJ} \mathrm{~mol}^{-1} ; D(\mathrm{Hf}-\mathrm{C})=$ $266 \mathrm{~kJ} \mathrm{~mol}^{-1}$. (b) The assumption of roughly equivalent $\pi$ bond energies is based on the nearly constant ratio of calculated force constants for the parent imido $\left(\mathrm{H}_{2} \mathrm{M}=\mathrm{NH}\right)$ and amido $\left(\mathrm{H}_{3} \mathrm{M}-\mathrm{NH}_{2}\right), k_{\mathrm{M}-\mathrm{N}} / k_{\mathrm{M}-\mathrm{N}} \approx 1.2$. Calculated metal-imido force constants $\left(k_{\mathrm{M}-\mathrm{N}}\right)$ in mdyn $\AA^{-1}$ are $8.27(\mathrm{Ti}), 7.37(\mathrm{Zr})$, and $7.90(\mathrm{Hf})$. Calculated metal-amido force constants $\left(k_{\mathrm{M}-\mathrm{N}}\right)$ in mdyn $\AA^{-i}$ are $3.78(\mathrm{Ti}), 3.39(\mathrm{Zr})$, and $3.63(\mathrm{Hf})$.

(33) (a) Wasserman, E. P.; Moore, C. B.; Bergman, R. G. Science 1992, 255, 315. (b) Weiler, B. H.; Wasserman, E. P.; Bergman, R. G.; Moore, C. B.; Pimentel, G. C. J. Am. Chem. Soc. 1989, $111,8288$.

(34) Morse, J. M.; Parker, G. M.; Burkey, T. J. Organometallics 1989, 8,2471 
"coordination" of alkanes to metal pentacarbonyls. Two interactions are of prime importance in the bonding of alkanes to metal centers: ${ }^{4}$ donation from $\sigma_{\mathrm{CH}}$ to a vacant metal $\mathrm{MO}$ coupled with back-donation from an occupied metal orbital to $\sigma^{*} \mathrm{CH}$. For a $\mathrm{d}^{0}$ (or $\mathrm{f}^{n} \mathrm{~d}^{0}$ ) metal, back-donation will be minimal. It seems likely that if a sufficiently electrophilic site were found, appreciable alkane interaction might occur in high-valent complexes. Watson ${ }^{6 c}$ has suggested their presence for the $\mathrm{Cp}_{2} \mathrm{LnCH}_{3}$ systems, plus there is the precedent of agostic bonding. ${ }^{35}$ Wolczanski and coworkers ${ }^{16}$ have recently obtained kinetic isotope effect data for $\mathrm{C}-\mathrm{H}$ activation by group IVB imidos which can be interpreted in favor of initial formation of alkane complexes.

Methane "coordinates" through a face of the tetrahedron to $(\mathrm{H})_{2} \mathrm{M}=\mathrm{NH}$ to yield a charge-transfer complex (2). The binding

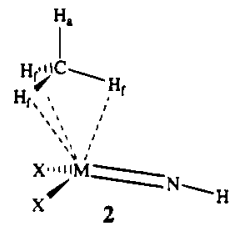

energies for the $\mathrm{Ti}-, \mathrm{Zr}-$, and $\mathrm{Hf}$-imido complexes are 8.9, 8.7, and $9.3 \mathrm{kcal} \mathrm{mol}^{-1}$, respectively. These charge-transfer (CT) complexes were obtained by taking the TS for $\mathrm{C}-\mathrm{H}$ activation (vide infra), distorting the geometry along the imaginary mode toward reactants, and then reoptimizing the geometry. ${ }^{36}$ Upon reoptimization, stationary points are obtained (2) in which the geometries of the $\mathrm{CH}_{4}$ and $(\mathrm{H})_{2} \mathrm{M}=\mathrm{NH}$ fragments are nearly identical to those calculated for the individually optimized reactants, with metal-carbon distances of $2.63(\mathrm{Ti}), 2.80(\mathrm{Zr})$, and $2.79 \AA$ (Hf). A Mulliken population analysis reveals that $0.15(\mathrm{Ti}), 0.23(\mathrm{Zr})$, and $0.17(\mathrm{Hf})$ electrons are transferred from methane to the metal; calculated charges do not change on the other atoms of the imido complex. The charges on $\mathrm{C}$ and $\mathrm{H}$ in isolated methane are -0.24 and +0.06 , respectively. In the CT complexes, the calculated atomic charges assume average values of $-0.48 \pm 0.02$ for $\mathrm{C}, 0.15 \pm 0.01$ for $\mathrm{H}_{f}$, and $0.22 \pm 0.01$ for $\mathrm{H}_{\mathrm{a}}$, 2. Thus, the $\mathrm{C}-\mathrm{H}$ bonds which were polarized $\left(\mathrm{C}^{\delta-} \mathrm{H}^{\delta+}\right)$ in isolated methane become more so in 2 . Wolczanski et al. ${ }^{8 \mathrm{a}}$ have proposed that the extremely polarized metal-imido bond induces greater $\mathrm{C}^{\delta-} \mathrm{H}^{\delta+}$ polarization, aiding in subsequent $\mathrm{C}-\mathrm{H}$ scission. The importance of the polarity of the metal-activating ligand bond has been pointed out by various researchers. ${ }^{6 b, d, 7 a}$ The present results support the "polarization hypothesis." The calculations further suggest that the formation of a methane complex is the agency through which greater polarization of the $\mathrm{H}_{3} \mathrm{C}-\mathrm{H}$ bond is brought about, facilitating what has been envisaged ${ }^{3,6-8}$ as a concerted heterolytic $\mathrm{C}-\mathrm{H}$ cleavage.

3. Transition States. The most plausible TS geometry for methane activation by a high-valent complex is a four-center one, since no change in the formal oxidation state of the metal occurs. ${ }^{3}$ An initial search for a TS connecting $\mathrm{CH}_{4}$ and $(\mathrm{H})_{2} \mathrm{Zr}=\mathrm{NH}$ with $(\mathrm{H})_{2} \mathrm{Zr}\left(\mathrm{CH}_{3}\right)\left(\mathrm{NH}_{2}\right)$ was done in $C_{s}$ symmetry. A $C_{s}$ stationary

(35) Green, M. L. H.; Brookhart, M.; Wong, L. K. Prog. Inorg. Chem. 1988, 36, 1

(36) (a) These CT complexes, obtained by distorting along the IRC and reoptimizing, have very small imaginary modes $\left(\approx 50 i \mathrm{~cm}^{-1}\right)$ corresponding to methane rotation. Rotation of methane yields degenerate conformations (b) Since the interaction is only between methane and the highly electrophilic metal fragments, these CT complexes resemble the ion-dipole complexes studied in the gas phase. ${ }^{36 c}$ The interaction can be calculated using the following equation where $\alpha$ is the

$$
V_{\text {id }}=\left[-166 \times \alpha\left(\text { in } 10^{-24} \mathrm{~cm}^{3}\right) \times q^{2} \text { (in au) }\right] / r^{4} \text { (in } \AA \text { ) }
$$

polarizability of methane $\left(2.593 \times 10^{-24} \mathrm{~cm}^{3}\right), q$ is the charge of the metal, and $r$ is the internuclear separation between them. The atomic charges calculated from the Mulliken population analysis are $q_{\mathrm{Ti}}=0.67 ; q_{\mathrm{Zr}}=1.06$ $q_{\mathrm{Hf}}=0.95$; metal-carbon distances in the CT complexes are $r_{\mathrm{TiC}}=2.63 \AA$ $r_{2 \mathrm{C}}=2.80 \AA ; r_{\mathrm{HC}}=2.79 \AA$. Thus, estimates of the interaction ar $-4,-8$, and $-6 \mathrm{kcal} \mathrm{mol}^{-1}$, somewhat less exothermic than calculated values. This may indicate that there is some covalent interaction between the metal and the methane, although calculations at higher levels of theory would be needed to confirm this. (c) Weisshaar, J. C. Ronan, M. Tonkyn, R. J. Phys. Chem. $1988,92,92$. point was found which possessed two imaginary frequencies, $1940 i$ (H-transfer from $\mathrm{C}$ to $\mathrm{N}$ ) and $172 i$ (rotation about the methyl group). The latter mode destroys $C_{s}$ symmetry and leads to a $C_{1}$ transition state which is $2 \mathrm{kcal} \mathrm{mol}^{-1}$ lower (at the RHF level with ZPE correction). The geometry of the $C_{1}$ and $C_{s}$ stationary points are essentially identical, other than in torsional angles involving the methyl group. Despite the reduction in symmetry, the atoms which comprise the four-center TS are nearly planar, Figure 2; $\mathrm{M}-\mathrm{N}-\mathrm{H}_{\mathrm{t}}-\mathrm{C}$ torsional angles are $0.02^{\circ}(\mathrm{Ti}),-0.03^{\circ}(\mathrm{Zr})$, and $0.004^{\circ}$ (Hf).

The enthalpies of $\mathrm{C}-\mathrm{H}$ activation $\left(\Delta H^{*}{ }_{\text {act }}\right.$ ) for methane by $(\mathrm{H})_{2} \mathrm{M}=\mathrm{NH}$ are calculated to be $14.5,14.1$, and $7.3 \mathrm{kcal} \mathrm{mol}^{-1}$ versus separated reactants for the $\mathrm{Ti}, \mathrm{Zr}$, and Hf systems, respectively, Table I. Replacement of the hydrido ligands in the $\mathrm{Zr}$ complex lowers the barriers to activation: 12.9 and $12.0 \mathrm{kcal}$ $\mathrm{mol}^{-1}$ for the bis(amido)- and dichloro- $\mathrm{Zr}$ complexes, respectively, Table I. As mentioned, direct experimental data for the methane activation step by group IVB imidos is limited. ${ }^{8 a}$ Intramolecular $\mathrm{C}-\mathrm{H}$ activation by the $\mathrm{Ta}=\mathrm{C}$ double bond in $\mathrm{Ta}(0-2,6-(t$ $\mathrm{Bu})_{2}$-4-X-phenyl $)_{2}\left(\mathrm{CH}_{3}\right)\left(=\mathrm{CH}_{2}\right)$ has $\Delta H^{*}{ }_{\text {act }}=14.3 \pm 1.0 \mathrm{kcal}$ $\mathrm{mol}^{-1}(\mathrm{X}=\mathrm{H})$ and $\Delta H^{\ddagger}{ }_{\text {act }}=15.4 \pm 1.0 \mathrm{kcal} \mathrm{mol}^{-1}(\mathrm{X}=\mathrm{OMe}){ }^{3}$ Based on the calculated $\Delta H^{*}$ act, Ti- and $\mathrm{Zr}$-imido complexes should display similar methane-activating ability in the absence of steric effects, while $\mathrm{Hf}$-imidos should be the most reactive. Similar activation parameters are found in the intramolecular activation of aryloxide $\mathrm{C}-\mathrm{H}$ bonds by analogous, four-coordinate $\mathrm{Ti}$ and $\mathrm{Zr}$ complexes, $\mathrm{M}\left(0-2,6-(t-\mathrm{Bu})_{2} \text {-phenyl }\right)_{2}(\mathrm{Bz})_{2} \Delta H^{*}{ }_{\text {act }}=$ $23.0 \pm 0.7 \mathrm{kcal} \mathrm{mol}^{-1}(\mathrm{M}=\mathrm{Ti}) ; \Delta H^{*}=21.6 \pm 1.0 \mathrm{kcal} \mathrm{mol}^{-1}$ $(\mathrm{M}=\mathrm{Zr}){ }^{37}$ Thus, the present calculations suggest that the inactivity found by Rothwell et al. ${ }^{15}$ is due to steric reasons, e.g., the unavailability of an open coordination site for the hydrocarbon or the inability of the hydrocarbon to displace py'.

Combining the calculated $\Delta H^{*}$ act with the exothermicities quoted above shows that the reverse process, methane elimination, has a barrier $\left(\Delta H^{*}{ }_{\text {elim }}\right)$ of $23.4(\mathrm{Ti}), 34.1(\mathrm{Zr})$, and $38.0 \mathrm{kcal} \mathrm{mol}^{-1}$ (Hf), depending on the metal for the dihydrido complexes, Table I. Published and unpublished data from Wolczanski et al. ${ }^{8 a, 16}$ are consistent with the trends as well as the magnitudes, in the barriers to methane elimination as a function of the metal. Activation parameters for the elimination of methane from $\left(\mathrm{Si}^{\prime} \mathrm{O}\right)_{2} \mathrm{Ti}$ $\left(\mathrm{NHSi}^{\prime}\right)\left(\mathrm{CH}_{3}\right)$ are $\Delta H^{*} \approx 21 \mathrm{kcal} \mathrm{mol}^{-1}$ and $\Delta S^{*} \approx-11 \mathrm{eu}^{16}$ Replacement of the hydrido ligands in the $\mathrm{Zr}$ complex with $\mathrm{Cl}$ and $\mathrm{NH}_{2}$ ligands lowers and raises, respectively, the barrier to methane elimination by roughly $0.8 \mathrm{kcal} \mathrm{mol}^{-1}$. The experimental ${ }^{8 \mathrm{a}}$ $\Delta H^{*}{ }_{\text {elim }}$ for $\left(\mathrm{NHSI}^{\prime}\right)_{3} \mathrm{ZrCH}_{3}$, measured over the temperature range $87.1-127.1^{\circ} \mathrm{C}$, is 25.9 (4) $\mathrm{kcal} \mathrm{mol}^{-1}$, in reasonable agreement with the calculated values, given the approximations made. One last set of calculations with an augmented basis set (adding $p$ polarization functions to $\mathrm{H}$ atoms) and correction of the calculated $\Delta H^{*}$ elim to $100^{\circ} \mathrm{C}$ was carried out for $\left(\mathrm{NH}_{2}\right)_{3} \mathrm{ZrCH}_{3}$. The basis set improvement and temperature correction lowers the calculated barrier to methane elimination to $31.4 \mathrm{kcal} \mathrm{mol}^{-1}$, in improved agreement with experiment.

The amount of bond stretching and compression in the TS is approximately the same for each system, Figure 2, as determined by the percentage change from equilibrium values in reactants and products. Metal-nitrogen bonds are stretched by $3-4 \%$ versus those in metal-imido reactant; metal-carbon bonds are stretched by $8-10 \%$ compared to those in methyl(amido) product. $\mathrm{C}-\mathrm{H}$ and $\mathrm{N}-\mathrm{H}$ bonds are further from equilibrium values, being $28-31 \%$ and $41-46 \%$ larger than normal $\left(r_{e}(\mathrm{CH})=1.10 \AA\right.$, $\left.r_{\mathrm{e}}(\mathrm{NH})=1.01 \AA\right)$, respectively. The effect of modifying the ancillary ligands $\left(X=\mathrm{H}, \mathrm{Cl}, \mathrm{NH}_{2}\right)$ on the $\mathrm{Zr}$ transition-state geometry is small. It seems plausible to assume that the ligands exert the majority of their influence through steric effects. The activation parameters for methane elimination from (NHiSi') $\mathrm{ZrCH}_{3}$ point to "substantial $\mathrm{Zr}-\mathrm{C}$ bond breaking $\left(\Delta H^{*}\right.$ $=25.9 \mathrm{kcal} / \mathrm{mol})$ in a relatively constrained transition state $\left(\Delta S^{*}\right.$ $=-7(1) \mathrm{eu})^{\prime \prime}$ in the transition state. ${ }^{8 \mathrm{a}, 38}$ The calculated structural

(37) Latesky, S. L.; McMullen, A. K.; Rothwell, I. P.; Huffman, J. C. J Am. Chem. Soc. 1985, 107, 5981. 

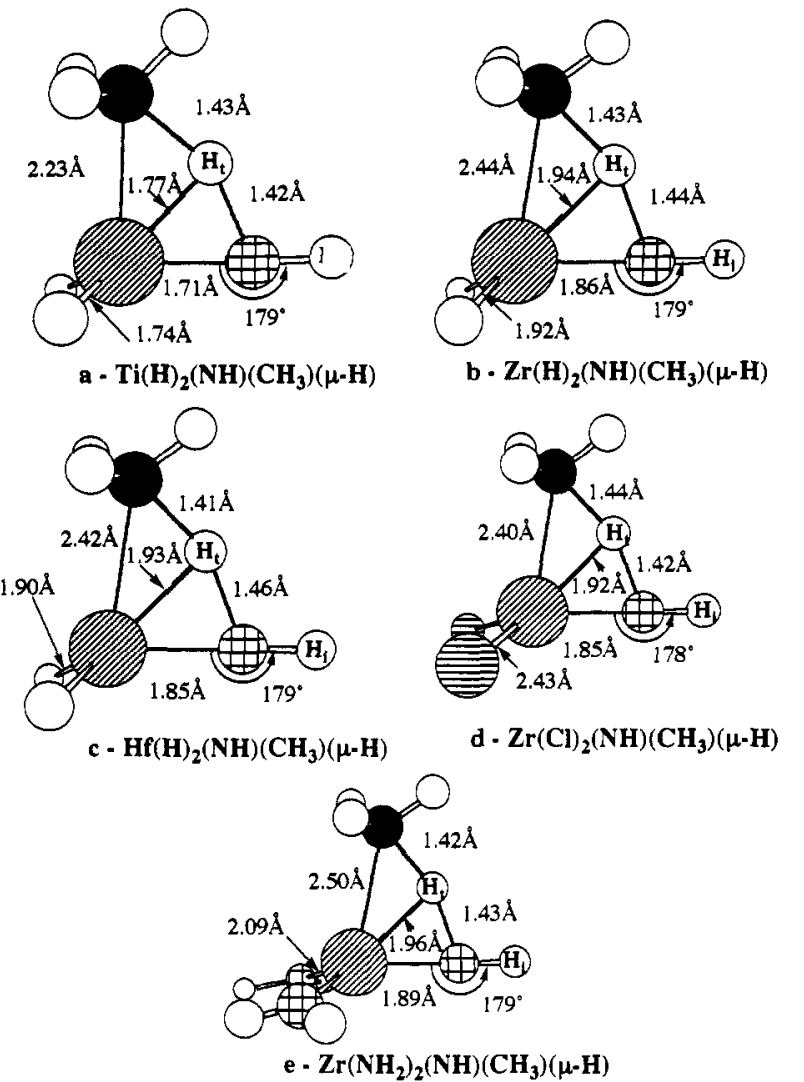

Figure 2. Calculated transition-state geometries for the methane activation/elimination processes. The circles with diagonal, horizontal, and crossed lines are metal, chlorine, and nitrogen atoms, respectively. The open circle is hydrogen; the filled circle is carbon. TSs a through $\mathrm{c}$ are $C_{1} ; \mathrm{d}$ and $\mathrm{e}$ are $C_{s}$.

data for TSs support a late transition state for methane elimination, in agreement with the experimental observation.

As mentioned in previous work ${ }^{10-14}$ on $\mathrm{H}_{2}$ and $\mathrm{CH}_{4}$ activation by high-valent metal systems, the geometry of the transition state 1 leads to a short metal-transannular hydrogen distance. On the average, the $\mathrm{MH}_{\mathrm{t}}$ distance is only 1-2\% longer than the corresponding terminal hydride bond length, Figure 2. Despite the short disparity in metal-hydrogen internuclear distances, the interaction (as estimated by the Mulliken bond overlap population (BOP)) is substantially less with $\mathrm{H}_{\mathrm{t}}$ than with the terminal hydride ligands. The BOP $\left(\mathrm{MH}_{1}\right)$ for each TS is $0.18(\mathrm{Ti}), 0.13(\mathrm{Zr})$, and $0.22(\mathrm{Hf})$, while the average BOP for the metal-terminal hydride bonds in the TS is $0.74(\mathrm{Ti}), 0.68(\mathrm{Zr})$, and $0.75(\mathrm{Hf})$. If we assume that the metal-terminal hydride BOP corresponds to a single bond value, then the fractional bond order for the $\mathrm{MH}_{\mathrm{t}}$ interaction is $0.24(\mathrm{Ti}), 0.19(\mathrm{Zr})$, and $0.29(\mathrm{Hf})(3)$. Therefore, the short $\mathrm{MH}_{\mathrm{t}}$ distance does not signify a formal single bond. However, there is a significant stabilizing interaction, as indicated by the positive sign of $\mathrm{BOP}\left(\mathrm{MH}_{\mathrm{t}}\right)$. As the $\mathrm{C}-\mathrm{H}_{\mathrm{t}}$ bond is stretched and activated, it seems reasonable to assume that $\mathrm{H}_{\mathrm{t}}$ will have available bonding capacity, some of which is used in forming the $\mathrm{N}-\mathrm{H}_{\mathrm{t}}$ bond and some of which is made available to the metal to stabilize $H_{t}$ as it migrates between $\mathrm{C}$ and $\mathrm{N}$.

4. Intrinsic Reaction Coordinate for Methane by the $\mathrm{Zr}$-Imido Complex. The intrinsic reaction coordinate (IRC) ${ }^{22}$ is the lowest-energy path connecting the reactants and products and is thus of great interest to the chemist. The IRCs for methane activation by various imidos at differing levels of theory are qualitatively similar. The primary points of interest can be gathered from an exposition of one example. A plot of the changes in pertinent bond

(38) The calculated enthalpies of activation for methane elimination from the $\mathrm{Zr}$-amido complexes are $-9.4(X=\mathrm{H}),-5.2\left(\mathrm{X}=\mathrm{NH}_{2}\right)$, and -5.7 eu $(X$ $=\mathrm{Cl}$ ) for an averge of $-7 \pm 2$ eu, in reasonable agreement with the experimental value $(-7 \pm 1 \mathrm{eu})$, given the approximations.
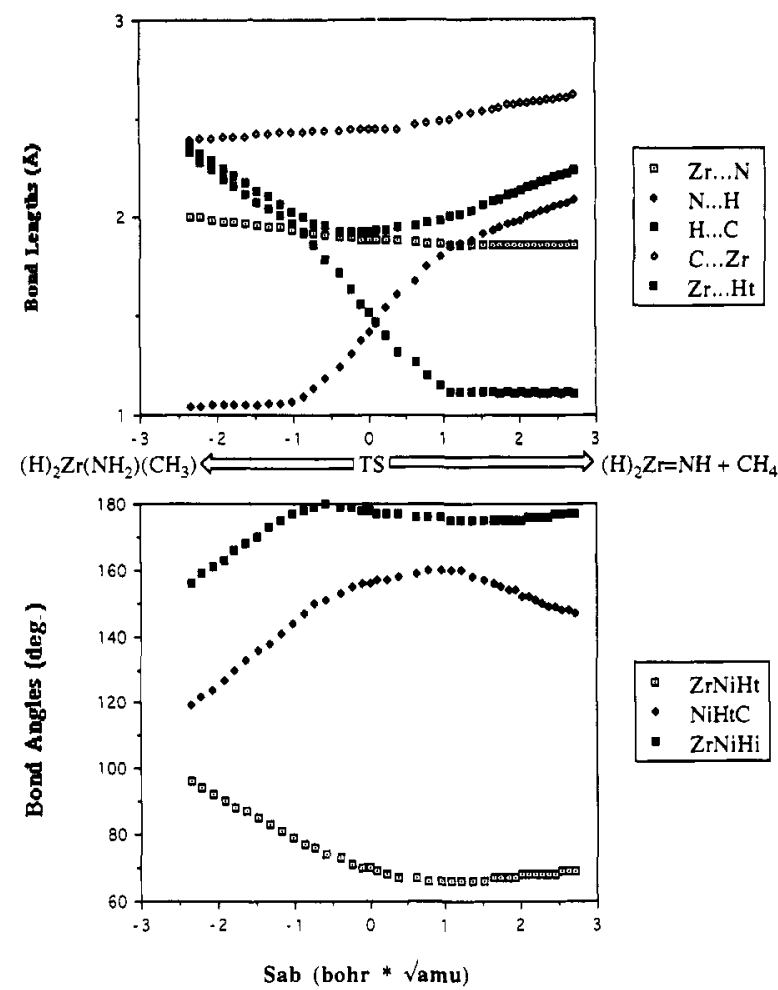

Figure 3. Plot of the changes in the important bond lengths and bond angles along the IRC for the activation of methane by $(\mathrm{H})_{2} \mathrm{Zr}=\mathrm{NH}$ at MCSCF level.

lengths and bond angles along the IRC of $(\mathrm{H})_{2} \mathrm{Zr}=\mathrm{NH}+\mathrm{CH}_{4}$ $\rightarrow(\mathrm{H})_{2} \mathrm{Zr}\left(\mathrm{CH}_{3}\right)\left(\mathrm{NH}_{2}\right)$, calculated at the MCSCF level, is shown in Figure 3. The abscissa in Figure 3 is the mass weighted distance along the reaction coordinate $\left(S_{\mathrm{ab}}\right.$, in bohr.amu $\left.{ }^{1 / 2}\right)$. The TS is set to $S_{\text {total }}=0$ bohr.amu ${ }^{1 / 2}$. For the four atoms which make up the four-center TS $\left(\mathrm{M}, \mathrm{N}, \mathrm{H}_{\mathfrak{t}}, \mathrm{C}\right)$ there are six internal coordinates $\left(\mathrm{N}-\mathrm{H}_{\mathrm{t}}, \mathrm{M}-\mathrm{H}_{\mathrm{t}}, \mathrm{C}-\mathrm{H}_{\mathrm{t}}, \mathrm{M}-\mathrm{N}-\mathrm{H}_{\mathrm{t}}, \mathrm{N}-\mathrm{H}_{\mathrm{t}}-\mathrm{C}, \mathrm{M}-\mathrm{N}-\mathrm{H}_{\mathrm{t}}-\mathrm{C}\right)$, only five of which are of interest since the four atoms remain essentially coplanar (i.e., $\mathrm{M}-\mathrm{N}-\mathrm{H}_{\mathrm{t}}-\mathrm{C} \approx 0^{\circ}$ ). In addition to these five internal coordinates, the $\mathrm{M}-\mathrm{N}-\mathrm{H}_{i}$ angle is a good indicator of the progress the nitrogen ligand is making in its transformation from an imido to an amido.

Proceeding from the extreme right (imido plus methane reactants), close inspection of the IRC shows that until $S_{\mathrm{ab}} \approx 1$, little structural change is taking place other than canting in of the $\mathrm{C}-\mathrm{H}_{\mathrm{t}}$ bond to be activated toward the $\mathrm{Z}=\mathrm{N}$ bond upon which it will be broken. The C- $\mathrm{H}_{\mathrm{t}}$ bond changes very little until $S_{\mathrm{ab}}$ $\approx 1$, after which it begins to lengthen considerably. From Figure 3 , there are several motions along the IRC which seem to be correlated. The "break" point at $S_{\mathrm{ab}} \approx 1$ for the C- $\mathrm{H}_{\mathrm{t}}$ bond coincides with a change in direction of the $\mathrm{N}-\mathrm{H}_{t}-\mathrm{C}$ angle; the $\mathrm{Zr}-\mathrm{N}-\mathrm{H}_{t}$ angle, which was unchanged up to this point on the reaction coordinate, begins to increase sharply. Plotting the geometries along the IRC reveals that these motions (from $S_{\mathrm{ab}} \approx$ 1 to $S_{\mathrm{ab}} \approx-1$ ) correspond to the transfer of $\mathrm{H}_{\mathrm{t}}$ from $\mathrm{C}$ to $\mathrm{N}$ in a fashion which is reminiscent of the motion of the central hydrogen in a A ...H...B hydrogen bond. At $S_{\mathrm{ab}} \approx-1$, a "break" point occurs for the $\mathrm{N}-\mathrm{H}_{\mathrm{t}}$ bond of the incipient amido, i.e., it has been formed and no further change is required. Note that the "break" point at $S_{\mathrm{ab}} \approx-1$ is correlated with a sharp decline in the $\mathrm{Zr}-\mathrm{N}-\mathrm{H}_{\mathrm{i}}$ angle, Figure 3 . Since the $\mathrm{Zr}-\mathrm{N}-\mathrm{H}_{\mathrm{t}}$ and $\mathrm{Zr}-\mathrm{N}-\mathrm{H}_{\mathrm{i}}$ change at the same rate after $S_{\mathrm{ab}} \approx-1$, Figure 3 , the amido ligand is pivoting in place as it is rehybridized from $\mathrm{sp}$ (imido) to $\mathrm{sp}^{2}$ (amido). It is interesting that the imido ligand does not pivot until the $\mathrm{NH}_{\mathrm{t}}$ bond is almost completely formed. After $S_{\mathrm{ab}} \approx-1$, all important changes have taken place and all that is left is for the angles about $\mathrm{Zr}$ to relax to the tetrahedral geometry of the methyl(amido) product.

The two most interesting points to emerge from the IRC are the timing of $\mathrm{N}-\mathrm{H}_{\mathrm{t}}$ bond formation with the pivoting of the amido 
ligand and the parabolic shape of the $\mathrm{MH}_{\mathrm{t}}$ curve along the reaction coordinate. If one considers the reverse reaction, extrusion of methane from $\mathrm{Zr}(\mathrm{H})_{2}\left(\mathrm{NH}_{2}\right)\left(\mathrm{CH}_{3}\right)$, the reaction occurs in several phases: the $\mathrm{C}-\mathrm{Zr}-\mathrm{N}$ bond angle compresses (step i), the amido ligand pivots (step ii), and then the $\mathrm{N}-\mathrm{H}_{t}$ bond breaks and is transferred to the methyl group to eliminate methane (step iii in eq 1). At $S_{\mathrm{ab}} \approx-1$, the $\mathrm{Zr}-\mathrm{N}-\mathrm{H}_{\mathrm{t}}$ angle is $\approx 87^{\circ}$ and $\mathrm{Zr}-\mathrm{N}-\mathrm{H}_{\mathrm{i}}$

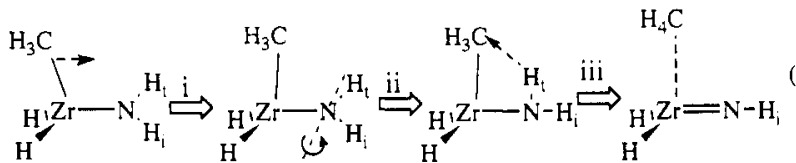

$\approx 168^{\circ}$ with a $\mathrm{H}_{\mathrm{t}}-\mathrm{N}-\mathrm{H}_{\mathrm{i}}$ angle of $105^{\circ}$. Thus, at $S_{\mathrm{ab}} \approx-1$, the $\mathrm{Zr}$ complex bears a striking structural resemblance to the isoelectronic (in terms of valence electrons) $\mathrm{Ta}=\mathrm{CH}$ moiety in electron-deficient alkylidenes $\mathrm{L}_{n} \mathbf{M}=\mathrm{C}(\mathrm{R}) \mathrm{R}^{\prime}{ }^{39}$ These complexes have $\mathrm{Ta}=\mathrm{C}-\mathrm{H}$ angles close to $90^{\circ}$, as revealed by neutron diffraction. ${ }^{39}$ The distorted $\mathrm{Ta}=\mathrm{C}-\mathrm{H}$ angles and longer than normal $\mathrm{C}-\mathrm{H}$ bonds suggest agostic $\mathrm{C}-\mathrm{H}$ interactions with the metal and incipient $\mathrm{C}-\mathrm{H}$ bond breaking. ${ }^{35,39}$ Calculated BOPs in the region of $S_{\mathrm{ab}} \approx-1$ are one-third less for agostic $\mathrm{N}-\mathrm{H}_{\mathrm{t}}$ compared to $\mathrm{N}-\mathrm{H}_{\mathrm{i}}$, although the former is only $0.05-0.07 \AA$ longer than the latter $\left(\mathrm{N}-\mathrm{H}_{\mathrm{i}}=1.00 \AA\right)$. The importance of agostic interactions in $\alpha$-elimination and $\mathrm{C}-\mathrm{H}$ activation processes involving metalcarbon species has been recognized since the phenomenon was first characterized. ${ }^{35}$ The calculations indicate that agostic interactions are also important in methane activation/elimination by their nitrogen analogues.

The second interesting point in the IRC concerns the behavior of $\mathrm{MH}_{\mathrm{t}}$ along the reaction coordinate. THe $\mathrm{M}-\mathrm{H}_{\mathrm{t}}$ distance decreases along the IRC from reactants toward TS, reaches a minimum in the vicinity of the TS, and then increases as methyl(amido) products are formed, Figure 3 . The minimum in the $\mathrm{M}-\mathrm{H}_{\mathrm{t}}$ distance coincides with the crossing of the $\mathrm{NH}_{\mathrm{t}}$ and $\mathrm{CH}_{\mathrm{t}}$ curves, i.e., these latter distances are equal. The correspondence of this crossing point with the minimum in the $\mathrm{MH}_{\mathrm{t}}$ curve suggests that the $\mathrm{MH}_{1}$ interaction is strongest (i.e., the distance is shortest) when $\mathrm{H}_{\mathrm{t}}$ is roughly halfway between $\mathrm{N}$ and $\mathrm{C}$ and, presumably, $\mathrm{H}_{t}$ has its maximum available bonding power. This correspondence has been seen elsewhere ${ }^{13}$ and can be interpreted as additional evidence for the importance of the $\mathrm{MH}_{\mathrm{t}}$ interaction in modulating the methane activation TS.

\section{Summary and Conclusions}

Several interesting points have resulted from this study of methane activation by group IVB imido complexes. Some of the more pertinent conclusions are summarized here.

(1) The exothermicity of methane activation $\left(\left(\mathrm{H}_{2}\right) \mathrm{M}=\mathrm{NH}+\right.$ $\mathrm{CH}_{4} \rightarrow(\mathrm{H})_{2} \mathrm{M}\left(\mathrm{NH}_{2}\right)\left(\mathrm{CH}_{3}\right)$ ) increases as the metal becomes heavier ( $\mathrm{Hf}>\mathrm{Zr}>\mathrm{Ti}$ ), while the activation barriers decrease in the opposite order ( $\mathrm{Ti}>\mathrm{Zr}>\mathrm{Hf}$ ). We hypothesize (vide supra) that this may be due to the greater driving force provided by a stronger metal-methyl bond in the presence of near equivalent metal-nitrogen $\pi$-bond energies. Jones and Feher ${ }^{40 a}$ present strong evidence for thermodynamic control in $\mathrm{C}-\mathrm{H}$ activation by the late, low-valent $\mathrm{CpRh}\left(\mathrm{PR}_{3}\right)$, although recent data by Schaller and Wolczanski40b reveal kinetic control in $\mathrm{C}-\mathrm{H}$ activation by a high-valent, Ta-bis(imido)amido complex. Additional experimental and computational information is needed for an assessment of the relative importance of ground-state and transition-state energy differences on the course of the methane activation reaction by high-valent complexes.

(2) A growing body of evidence, gas-phase ${ }^{41}$ and solution-

(39) Schrock, R. R. Acc. Chem. Res. 1979, 12, 98

(40) (a) Jones, W. D.; Feher, F. J. Acc. Chem. Res. 1989, 22, 91. (b) Schaller, C. P.: Wolczanski, P. T. Inorg. Chem. Submitted for publication

(41) (a) Weisshaar et al ${ }^{36 c}$ have measured gas-phase binding energies for $\mathrm{CH}_{4}$ to $\mathrm{Mn}^{+}$and $\mathrm{Zn}^{+}$of $>10 \mathrm{kcal} \mathrm{mol}^{-1}$. High-level ab initio calculations yield values of $8-28 \mathrm{kcal} \mathrm{mol}^{-1}$ for $\mathrm{Co}^{+} . . \mathrm{CH}_{4}$, depending on the basis set and level of electron correlation. ${ }^{416}$ Computational work ${ }^{13}$ on related $\mathrm{H}_{2}$ complexes of a coordinatively saturated, neutral species. $\left((\mathrm{H})_{2} \mathrm{Z}=\mathrm{NH}\right.$ ) showed much less dependence on basis set and level of correlation. (b) Koga, N.; Musaev, J. Morokuma, K.; Gordon, M. S.; Cundari, T. R. Manuseript in preparation. phase, ${ }^{16,33,34}$ suggests the presence of alkane complexes on the potential energy surface for methane activation. The initial interaction of methane and $(\mathrm{H})_{2} \mathrm{M}=\mathrm{NH}$ leads to the formation of alkane complexes which are bound by $\approx 9 \mathrm{kcal} \mathrm{mol}^{-1}$. At this point it is not clear what role, if any, these species play in the all-important scission step that follows. Several possibilities come to mind, e.g., keeping the $\mathrm{C}-\mathrm{H}$ bond to be activated in the presence of the metal-imido "active site" for a longer period of time, weakening $\mathrm{C}-\mathrm{H}$ by the transfer of electron density out of the $\mathrm{C}-\mathrm{H}$ bonding region, and taking part in the aforementioned polarization phenomenon. A Mulliken population analysis indicates that $\approx 0.2$ electrons are transferred from $\mathrm{CH}_{4}$ to the metal, inducing greater $\mathrm{C}^{\delta} \mathrm{H}^{\delta+}$ polarization. It has been proposed ${ }^{8 a}$ that the metal-imido bond induces a polarization of the $\mathrm{C}-\mathrm{H}$ bond, which aids in the $\mathrm{C}-\mathrm{H}$ activation process. The present results support such a proposal and suggest that the alkane complex is the vehicle through which increased $\mathrm{C}^{\delta}-\mathrm{H}^{\delta+}$ polarization is set in motion, facilitating the subsequent rupture in a concerted, heterolytic $\mathrm{C}-\mathrm{H}$ cleavage. Further studies, computational and experimental, are in order to characterize the chemistry of these complexes and assess their importance in methane activation by high-valent, $\mathrm{d}$ and $\mathrm{f}$ block complexes.

(3) The enthalpies of $\mathrm{C}-\mathrm{H}$ activation $\left(\Delta H^{*}\right.$ act $)$ for the addition of a methane $\mathrm{C}-\mathrm{H}$ bond across the $\mathrm{M}=\mathrm{N}$ bond of $(\mathrm{H})_{2} \mathrm{M}=\mathrm{NH}$ are calculated to be $14.5(\mathrm{Ti}), 14.1(\mathrm{Zr})$, and $7.3 \mathrm{kcal} \mathrm{mol}^{-1}(\mathrm{Hf})$ above those of separated reactants, Table I. Although experimental evidence for this process is limited, the calculated $\Delta H^{*}$ act values for the metal-imido complexes are in reasonable agreement with estimates available from metal-carbon complexes. ${ }^{3}$ As noted above, $\Delta H^{*}$ act shows the expected correlation with $\Delta H_{\mathrm{rxn}}$, i.e., $\Delta H^{*}{ }_{\text {act }}$ decreases as $\Delta H_{\mathrm{rxn}}$ becomes more exothermic.

(4) Calculated $\Delta H^{*}$ elim are $23.4(\mathrm{Ti}), 34.1(\mathrm{Zr})$, and $38.0 \mathrm{kcal}$ $\mathrm{mol}^{-1}$ for the dihydrido complexes. Data from Wolczanski et al. $^{8 a, 16}$ are supportive of the trends, as well as the magnitudes, in $\Delta H^{*}{ }_{\text {elim }}$ as a function of the metal. $\Delta H^{*}$ elim $=25.9(4) \mathrm{kcal} \mathrm{mol}^{-1}$ for methane elimination by $\left(\mathrm{NHSi}^{\prime}\right)_{3} \mathrm{ZrCH}_{3}{ }^{8 \mathrm{a}}$ Methane elimination from $\left(\mathrm{NH}_{2}\right)_{3} \mathrm{ZrCH}_{3}$ is $\Delta H^{*}$ elim $\left(100^{\circ} \mathrm{C}\right)=31.4 \mathrm{kcal} \mathrm{mol}^{-1}$ at the highest level of theory. Higher levels of correlation will probably lower $\Delta H^{*}$ elim, since the TS is more sensitive to improvements in correlation and basis set due to the presence of bonds which are far removed from equilibrium values.

(5) The amount of bond stretching and compression in the TS versus equilibrium values is approximately the same for all systems studied. The calculated geometries of the methane activation/ elimination TSs indicate a late transition state for methane elimination (and thus an early TS for the reverse process), in agreement with experimentally determined activation parameters. $^{8 \mathrm{a}, 16}$

(6) The IRC analysis indicates that $\mathrm{NH}$ bond activation occurs after pivoting of the amido ligand if the reaction is reviewed as the microscopic reverse of methane activation, i.e., $\alpha$-elimination of methane. After pivoting of the amido ligand occurs but before $\mathrm{H}$-transfer from $\mathrm{N}$ to $\mathrm{C}$ is significant, the $\mathrm{Zr}$-amido geometry at this point on the reaction coordinate resembles that of the $\mathrm{Ta}=\mathrm{CH}$ fragment in Schrock's electron-deficient Ta-alkylidenes. ${ }^{39,42}$ An analysis of the Mulliken bond overlap population indicates that the agostic $\mathrm{N}-\mathrm{H}$ is significantly weaker than the spectator $\mathrm{N}-\mathrm{H}$. Thus, an analysis of the reaction path for the methane activation/elimination process for nitrogen ligands reveals a reaction coordinate similar to that envisioned for $\alpha$-elimination of alkanes by high-valent alkyls and alkylidenes. ${ }^{39}$ Studies are underway in our labs to further address these similarities.

(7) The Mulliken bond overlap populations (BOPs) indicate a stabilizing interaction between the metal and the transannular $\mathrm{H}\left(\mathrm{H}_{\mathrm{t}}\right)$ in the TS for methane activation/elimination by group

(42) Two recent crystal structures of monoorganyl amido (i.e., $N(H) R$ ) complexes of $\mathrm{Zr}(\mathrm{IV})$ show large $\left(\approx 160^{\circ}\right) \mathrm{Zr}-\mathrm{N}-\mathrm{C}$ angles and shorter than normal $\mathrm{Zr}$-amido bonds $(\approx 2.00 \AA)$, and although the $H$ atoms were not located, one can presume small $\mathrm{Zr}-\mathrm{N}-\mathrm{H}$ angles. (a) Bai, Y.; Roesky, H.; Noltemeyer, M.; Witt, M. Chem. Ber. 1992, 125, 825. (b) Cummins, C. C.; van Duyne, G. D.; Schaller, C. P.; Wolczanski, P. T. Organometallics 1991, 10, 164 . 
IVB imido complexes. Further evidence for the potential importance of this interaction in stabilizing the TS versus reactants was found in the IRC; the $\mathrm{MH}_{\mathrm{t}}$ distance is at a minimum when $\mathrm{H}_{t}$ is midway between $\mathrm{C}$ and $\mathrm{N}$, presumably the point at which it has the greatest need of a bonding interaction. The $\mathrm{MH}_{\mathrm{t}}$ interaction is one-quarter of that in a normal metal-terminal hydride bond, as measured by the BOP. Low-energy, vacant $d$ oribtals on the metal seem a likely source for interaction with $\mathrm{H}_{\mathrm{t}}$. Consistent with this proposal is the much higher barrier for 1,2-methane elimination in $(\mathrm{H})_{2} \mathrm{Si}\left(\mathrm{CH}_{3}\right)\left(\mathrm{NH}_{2}\right)\left(83.3 \mathrm{kcal} \mathrm{mol}^{-1}\right)$, in which $\mathrm{d}$ orbital participation will be less or nonexistant. ${ }^{43}$ It is tempting to infer that the design of catalyst and material precursors $\left(\mathrm{L}_{n} \mathrm{M}(\mathrm{X}) \mathrm{E}\left(\mathrm{H}_{t}\right)\right)$ which enhance the $\mathrm{MH}_{\mathrm{t}}$ interaction will lower barriers to alkane activation and elimination and lead to catalysts which are more active and CVD precursors which can be processed at lower temperatures. Studies are in progress ${ }^{43}$ to assess the effect on the $\mathrm{MH}_{\mathrm{t}}$ interaction (and its correlation to

(43) Cundari, T. R.; Gordon, M. S. J. Am. Chem. Soc. Submitted for publication. barrier heights) which results from modification of the leaving group $(\mathrm{X})$, metal $(\mathrm{M})$, and ligand $(\mathrm{E})$.

Acknowledgment. The author wishes to thank Mark Gordon, Mike Schmidt, and the rest of the Iowa State Quantum Chemistry Group for providing us with the latest copy of GAMESS and helpful discussions. Helpful discussions and the communication of unpublished results by Peter T. Wolczanski (Department of Chemistry, Cornell University) and Jan H. Jensen (Department of Chemistry, Iowa State University) are also gratefully acknowledged. A grant to T.R.C. of time on the Cray Y-MP8/864 (Grant No. CHE920007N) at the National Center for Supercomputing Applications (NCSA), administered by the National Science Foundation, was instrumental in carrying out several of the larger calculations reported here. The bulk of the calculations described here were carried out at MSU on a DECstation $5000 / 200$, which was a generous loan of the Digital Equipment Corporation. Additional funding was provided by the Department of Chemistry and Memphis State University (through a Faculty Research Grant).

\title{
Incorporation of Hydration Effects within the Semiempirical Molecular Orbital Framework. AM1 and MNDO Results for Neutral Molecules, Cations, Anions, and Reacting Systems
}

\author{
George P. Ford* and Bingze Wang \\ Contribution from the Department of Chemistry, Southern Methodist University, \\ Dallas, Texas 75275. Received May 29, 1992
}

\begin{abstract}
A recently developed continuum model for the incorporation of hydration effects into the AM1 and MNDO semiempirical molecular orbital Hamiltonians is evaluated by comparison with representative experimental data. The new method gives quantitatively correct predictions for the aqueous-phase conformational behavior of $\mathrm{H}_{3} \mathrm{~N}^{+} \mathrm{CH}_{2} \mathrm{CH}_{2} \mathrm{CO}_{2}^{-}$and the aqueous-phase activation energetics of the $\mathrm{S}_{\mathrm{N}} 2$ reaction of $\mathrm{Cl}^{-}$and $\mathrm{CH}_{3} \mathrm{Cl}$. The dissociation energetics of $t \cdot \mathrm{BuCl}$ are correctly predicted, while the computed dissociation pathway includes a shallow energetic minimum corresponding to the expected tight ion pair. The absolute hydration energies of neutral molecules and cationic and anionic species are generally predicted satisfactorily. Systematic deviations from the experimental data due to the intervention of hydrophobic effects (not currently allowed for) as well as those traceable to the simplified integral treatment are noted. Contrary to intuition, continuum methods apparently can give quantitatively reliable hydration energies for species in which specific hydrogen-bonding effects are generally considered to be important. This was true for protonated amines, although only partially so for protonated oxygen bases.
\end{abstract}

\section{Introduction}

The reaction field approach has attracted much recent attention as a general basis for the computation of solvation energies. ${ }^{1,2}$ Despite the crudeness of the model, in which the solvent is treated as a structureless dielectric continuum, it appears to offer considerable promise in chemical, biochemical, and pharmacological applications. To date, development of the theory within the quantum mechanical framework has evolved in three distinct directions. In one, the solute is placed in an ellipsoidal or often simply a spherical cavity within the solvent with which it interacts via its dipole or in some cases higher-order multipole moments. ${ }^{3-5}$

(1) Tapia, O. In Quantum Theory of Chemical Reactions; Daudel, R. Pullman, A., Salem, L., Veillard, A., Eds.; Reidel: Dortrecht, 1980; Vol. 2, pp 25-72. Tapia, O. Molecular Interactions: Ratajczak, H., Orville-Thomas, W. J., Eds.; Wiley: New York, 1982; Vol, 3, pp 47-117.

(2) Drummond, M. L. J. Prog. Biophys. Molec. Biol. 1986, 47, 1-29.

(3) McCreery, J. H.; Christoffersen, R. E.; Hall, G. G. J. Am. Chem. Soc. 1976, $98,7191-7197$.

(4) Rinaldi, D.; Ruiz-Lopez, M. F.; Rivail, J.-L. J. Chem. Phys. 1983, 78 $834-838$
Although this method has enjoyed considerable popularity, there are obvious limitations associated with the need to constrain an arbitrarily shaped solute to a cavity of specified shape. For similar reasons, its application to reaction processes is highly limited.

In the so-called extended Born approach, the solute is treated as an array of atom-centered spheres, each of which contributes to the overall hydration energy in a manner related to Born's original treatment of monatomic ions. ${ }^{6-12}$ A number of appli-

(5) Karelson, M. M.; Tamm, T.; Katritzky, A. R.; Cato, S. J.; Zerner, M. C. Tetrahedron Comput. Methodol. 1989, 2, 295-304. Katritzky, A. R. Karelson, M. J. Am. Chem. Soc. 1991, 113, 1561-1566.

(6) Klopman, G. Chem. Phys, Lett. 1967, 1, 200-202

(7) Germer, H. A., Jr. Theor. Chim. Acta 1974, 34, 145-155; 35, 273-274.

(8) Constanciel, R.; Contreras, R. Theor. Chim. Acta 1984, 65, 1-11.

(9) Kozaki, T.; Morihashi, K.; Kikuchi, O. J. Mol. Struct. (THEOCHEM) 1988, 168, 265-277.

(10) Kozaki, T.; Morihashi, K.; Kikuchi, O. J. Am. Chem. Soc. 1989, 1/l, $1547-1552$.

(11) Tucker, S. C.; Truhlar, D. G. Chem. Phys. Lett. 1989, 157, 164-170.

(12) Cramer, C. J.: Trublar, D. G. Science 1992, 256, 231-217. Cramer.

C. J.: Truhlar, D. G. J. Am. Chem. Soc. 1991, l13, 8552-8554, 8305-8311. 